\title{
An Investigation into Setting Head Parameters in English as a Head-initial Language from the Minimalist Perspective
}

\author{
Zeinolabedin Rahmani \\ Islamic Azad University, Sama Branch, Qaemshar, Iran \\ Seyed Jalal Abdolmanafi (Rokni) \\ Golestan University, Gorgan, Iran \\ Email: j.abdolmanafi@yahoo.com
}

\begin{abstract}
Opposing to the behaviorist approach, the alternative approach proposed by Chomsky believes that language acquisition cannot be accounted for without considering a linguistically specific system of Principles and Parameters which every healthy child is expected to have genetically in his or her mind. A set of absolute Universals, Notions and Principles exist in the UG which do not vary from one language to another, while certain grammatical principles and rules may be universal. It is also true that languages differ from one another in some important ways like being either head-initial or head-last. Regarding English head parameters, all heads (whether nouns, verbs, prepositions, or adjectives etc.) normally precede their complements. In this study we tried to investigate why this language is considered as a head initial one despite the occurrence of different options for every NP, VP, AP and PP.
\end{abstract}

Index Terms - head parameter setting, head initial, head final, universal grammar

\section{INTRODUCTION}

The innate linguistic endowment named UG is not sufficient to enable humans to speak a language, if it was so, human beings would be able to speak any language regardless of where they are born and whose their parents are, so it would be linguistically wrong to expect that, for instance, a child growing up in a community where only English is spoken could become a native speaker of Persian; because while certain grammatical principles are universal, there is also some variation among different languages. For example the head parameter, captures the way languages differ in the position of heads within phrases. (Haegeman, 2008; Cook, 1988)

\section{HEAD PARAMETER}

A crucial innovation to the concept of phrase structure that emerged in the early 1970s (Chomsky, 1970) was the claim that all phrases have a central element, known as a head, around which other elements of the phrase revolve and can minimally stand for the whole phrases. An important aspect of language variation concerns the location of the head in relationship to the other elements of the phrase called complements. The head of the phrase can occur on the left of a complement or on its right (Cook \& Newson, 2007). In head-initial languages like English, the head of a phrase occurs on the left of the other elements in the phrase.

\section{A. Heads and Their Dependents}

In any phrase, the head is the necessary part of its phrase and other words are dependents to that head which can follow or precede it. In the following examples the italic words are the key word of the phrase namely heads and the other components are their dependents (Tallerman, 1998).

a. very bright $[\mathrm{N}$ sunflowers]

b. [V overflowed] quite quickly

c. very $[\mathrm{A}$ bright]

d. quite [ADV quickly]

e. $[\mathrm{P}$ inside $]$ the house

There are four different syntactic relationships between a head and its dependents. (The relevant heads are given in both bold and italic). 
TABLE 1:

SYNTACTIC RELATIONSHIPS BETWEEN HEADS AND DEPENDENTS (BASED ON THE DEFINITIONS AND ILLUSTRATION OF TALLERMAN, 1998: 103)

\begin{tabular}{|l|l|l|l|l|}
\hline & Head & Dependents & Language & Example \\
\hline 1 & Postposition/preposition & Object NP & English & On the table (preposition) \\
\hline 2 & Verb & Arguments of the verb & English & Ali loves the girl \\
\hline 3 & (possessed) noun & Possessor NP & English & Ali's car \\
\hline 4 & Noun & adjective & English & Big house \\
\hline
\end{tabular}

\section{B. Heads as the Most Important Elements in the Phrase}

Heads are the most important sections in their phrase due to the following reasons:

1. The head carries the most important semantic information, in other words it determines the meaning of the entire phrase. For example the phrase very bright sunflowers is about sunflowers and overflowed quite quickly is about something overflowing and so on. To take other examples, a stone bridge is a kind of bridge, not a kind of stone, so the head is bridge; and a garden flower is a kind of flower, not a kind of garden, so the head is flower. By paying attention to the examples we can conclude that the class of the head determines the word class of the entire phrase. Because very bright sunflowers is headed by a noun, it is a Noun Phrase (NP); and because overflowed quite quickly is headed by a verb, so it is a Verb Phrase (VP); and accordingly very bright is an Adjective Phrase (AP), quite quickly is an Adverb Phrase (ADVP) etc.

2. Heads are the only words that have the same distribution as the entire phrase because it's possible to substitute just the head for the whole phrase. For instance, it could be said that either Kim liked very bright flowers, or just Kim liked sunflowers; or it could be said, go inside the house or just go inside. By the same token the sunflowers were bright is grammatically correct but not *the sunflowers were very, Therefore, bright rather than very must be the head of the AP.

3. The third property of heads is that they are the one obligatory item in the phrase, for example the answer to the question Are you angry? can't be just very!

4. By taking the third property of heads into considerations, the forth property of heads will be that they may select an obligatory dependent, such as NP. To sum up we can say that phrases have heads and may additionally contain some optional or obligatory dependents (Tallerman, 1998: 91-92, Crystal, 2003: 215).

\section{The Position of Heads in Different Languages}

There is a strong tendency, cross-linguistically, for the head to occur in a fixed position in all phrases within a language. ... In head-initial languages the head precedes its complements, and in head-final languages the head follows its complements. (Cook \& Newson, 1996)

\section{Head-initial languages}

"In English all heads (whether nouns, verbs, prepositions, or adjectives etc.) normally precede their complements" (Radford, 2006: 19), and hence it is a head-initial language. The complements to V, P, A and N all are preceded by their heads in the following examples:
a. [VP loves Mary]
b. [PP into the water]
c. [AP fond of chips]
d. [NP admiration for Sara]

\section{Head-final languages}

Examples of head-final language can be Persian and Korean, in which heads in every phrase such as: AP, NP, VP and PP follow its complements.

\section{States of the Development of the Language Faculty}

Children are not born with the knowledge of all the lexical items in the language. Parameters and lexical items have not been set in the initial state and the language faculty has minimal contents.

"The two extreme states of the language faculty are the steady state when the mind knows a complete I-language and the initial state when it knows only the principles. Language acquisition comes down to how the human language faculty changes from the initial to the steady state ... the language faculty achieves adult knowledge of language, complete with parameter setting and lexicon for a particular language, by getting certain types of information about the structures and vocabulary of the language it is exposed to." (Cook \& Newson, 2007: 49-50)

\section{A. Principles and Parameters in First Language Acquisition}

"In Chomsky's conceptualization, the child is born with some Language Acquisition Device (LAD) which provides an abstract specification of the range of possible and impossible rules and structure in natural language. With the help of this inborn faculty, the child is able to account for the grammaticality and ungrammaticality of certain sentences and rules he is faced with. For instance, the Structure Dependency Principle proposed by Chomsky is considered as the part of the innate system of biologically endowed principle of UG which constitutes the human language faculty (Farrokhpey, 1999). 
"The child learning the grammar of some particular language ... simply has to find out the permissible order of elements in that language. Thereby the head parameter admits a limited range of above mentioned alternatives: headinitial or head-final. In Chomsky's view, universals provide the key to understanding language acquisition since only if we hypothesize that the child has innate knowledge of these universals can we account for the rapidity of language acquisition (ibid).

Chomsky argues that while language is acquired, it is not the environment or experience but the mind which has an important role. Indeed, if children are supposed to be acquiring language through making it a habit, namely by imitating it, they should also, be hearing the ungrammatical sentences which they produce from their environment. As one evident, when the language acquisition process is examined, it is seen that children know some grammatical rules although they have not come across with them. The fact is that children know more than they can speak which is obviously a sign that language is a product of the mind. Another evidence which shows the importance of the mind rather than the environment, is that although a child hears incorrect linguistic evidence, he can perform his language correctly. Even if adults pause and create unfinished and incorrect sentences while talking, the child can create infinite sentences even by depending on this limited data based on his innate faculty (Chomsky, 1988; Chomsky, 1976).

A child can develop his language with such limited data and input because the limited input is shaped by UG which is considered to be on people's mind by birth, in other words the data comes from within (from UG itself) not from outside. According to this, the process of language acquisition is seen as the access of the limited input that child hears, into a LAD and through processing inside the LAD, creative grammar is produced which is later named principle and parameter theory (Chomsky, 1972).

Accordingly, a new born baby's mind, by means of language acquisition is at its first state, which is called the Initial Zero State or $S_{0}$. (Cook \& Newson, 2007); Language acquisition continues until the Steady State or Ss (the mind of the adult native speaker) where language development is completed (ibid). From the above statements it can be concluded that, a child acquires his language based on the following formula: $\mathrm{S}_{0}-\mathrm{S} 1-\mathrm{S} 2 \rightarrow \mathrm{S}_{\mathrm{s}}$.

A child at the initial state will set the parameters on his mind depending on the input related to the language by activating the Principles and Parameters of UG; for instance, taking the head parameter into considerations, the child should start with one of the possible values of this parameter (head-initial or head-final) (Chomsky, 2005).

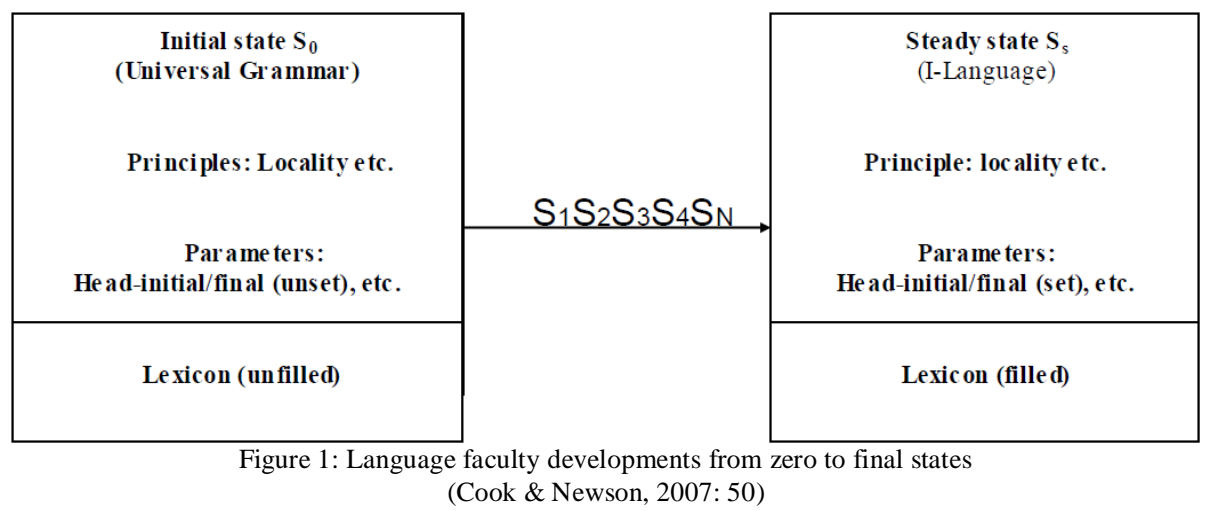

"The steady state is, to all intents and purposes, static; the speaker may become more or less efficient at using language or may add or lose a few vocabulary items, but linguistic competence is essentially complete and unchanging once it has been attained." (Chomsky, 2001: 1)

\section{Parameter-setting acquisition and positive evidence}

Acquiring a language means setting all the parameters of UG appropriately, they are limited in numbers but powerful in their effects. To acquire English rather than language $X$, the child must set the values for the head parameter, and a handful of other parameters; the child doesn't acquire rules but setting for parameters, which, interacting with the network of principles, create a core grammar (Cook \& Newson, 2007).

"Parameter setting might start in a neutral position in which any setting is possible and or start from a particular value (the unmarked setting) and need particular evidence to adopt the other setting (the marked setting)" (Cook \& Newson, 1996: 115).

One of the questions posed by the parameter-setting model of acquisition is how children are able to choose the appropriate setting for given parameters, as Chomsky claims, there are two types of evidence expected to be available for the language learner, namely positive and negative evidence. If children's speech input is made up of structures in which heads precede their complements like English, then this provides them with positive evidence and by this positive evidence they are able to set the head-position parameter appropriately (Radford, 2006).

\section{Parameter-setting by negative evidence}

Negative evidence is of two kinds which also causes children set their appropriate parameter of mother tongue: direct and indirect; direct negative evidence might come from the correction of children's errors by other speakers of the language and indirect negative evidence occurs when for example, a child's experience includes no examples of 
structures in which heads follow their complements (e.g. no prepositional phrases like *dinner after in which the head preposition after follows its complement dinner, and no verb phrases such as *cake eat in which the head verb eat follows its complement cake). On the basis of such indirect negative evidence (i.e. evidence based on the nonoccurrence of head-last structures), the child might infer that English is not a head-final language .... and when the child hears a prepositional phrase like with Daddy in which the head preposition with precedes its complement Daddy, he will have positive evidence that English allows head-initial order in prepositional phrases and there is the assumption that the head-position parameter is a binary one and that each parameter allows only a single setting, then it is inferred that when for example English allows head-first prepositional phrases, it will not allow head-final prepositional phrases. In order for the child to know that English allows head-initial prepositional phrases, he doesn't need negative evidence from the non-occurrence of such structures, but he can rely on positive evidence from the occurrence of the converse order in head-initial structures. (Radford, 2006)

Chomsky (1986) concludes that there is good reason to believe that children learn language only from positive evidence and they set their language parameters based on the positive evidence of mother tongue language. ${ }^{1}$ (Chomsky, 1986)

To sum up in Chomsky's words, "what we know innately are the principles of the various subsystems of $S_{0}$ and the manner of their interaction and the parameters associated with these principles. What we learn are the values of the parameters and the elements of the periphery (along with the lexicon to which similar considerations apply)". (Chomsky, 1986: 150)

\section{B. Principles and Parameters in L2 Acquisition}

While a child who acquires L1 is at initial state, the adult, learning L2, would be in a different position, because the adult would already be equipped with the knowledge of L1 containing the universal grammar of principles and parameters of his first language. Therefore, the initial state of SLA is shown by $\left(S_{i}\right)$ which actually is formed by: $S_{i}$ (initial state of L2) $=\left(\mathrm{S}_{0}+\mathrm{S}_{\mathrm{s}}\right)$. It should be taken into account that in L2, there is no steady state like L1, instead, there is a Terminal State $\left(S_{t}\right)$ which differs from one person to another.

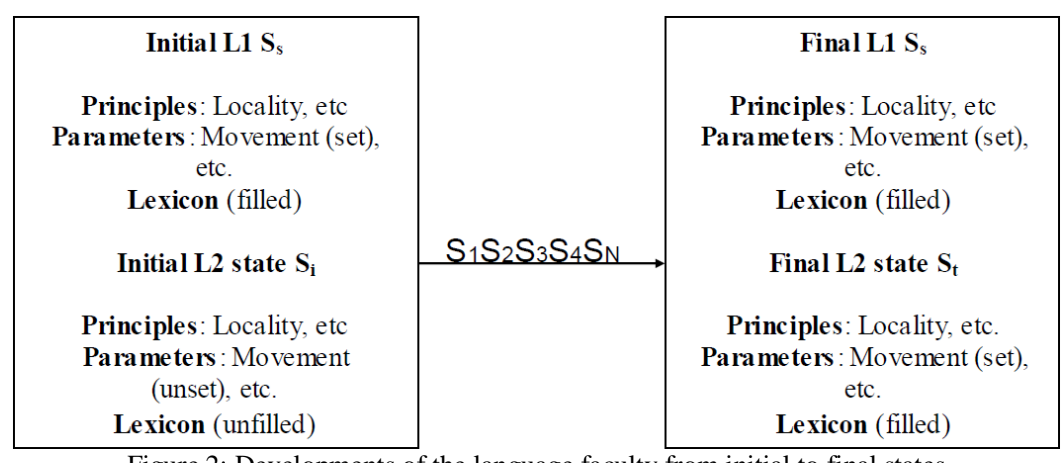

Figure 2: Developments of the language faculty from initial to final states

(Cook \& Newson, 2007: 230)

\section{Phrase structure of NPs}

NPs in different languages or dialects can be followed or preceded by different number(s) of complements; these phrases are analyzed in the following paragraphs in order to recognizing the position(s) of their heads and complements.

\section{Is English head-initial in its NPs?}

A phrase in X-bar theory always contains at least a head as well as other constituents. In NPs, N is the head plus some specifiers and complements as well as adjuncts (Haegeman, 2008). Since more complements in English NPs, follow their head nouns than the complements which precede them, they are considered as head-initial.

\section{Complements preceding their head nouns}

There are three complements which precede their head nouns in English NPs: 1- Specifiers, 2- Attributive adjectives and 3- Nominal dependents. Specifiers, attributive adjectives and nominal dependents are positioned before head nouns in English and are ordered based on the phrase structure rules of: 1- $X^{\prime \prime} \rightarrow \operatorname{Spec} X^{\prime}, 2-X^{\prime} \rightarrow$ Complement X.

${ }^{1}$ Guasti (2002) also in his research claimed that children do not make use of negative evidence in setting parameters. 
TABLE 2:

COMPLEMENTS PRECEDING THEIR HEAD NOUNS IN ENGLISH

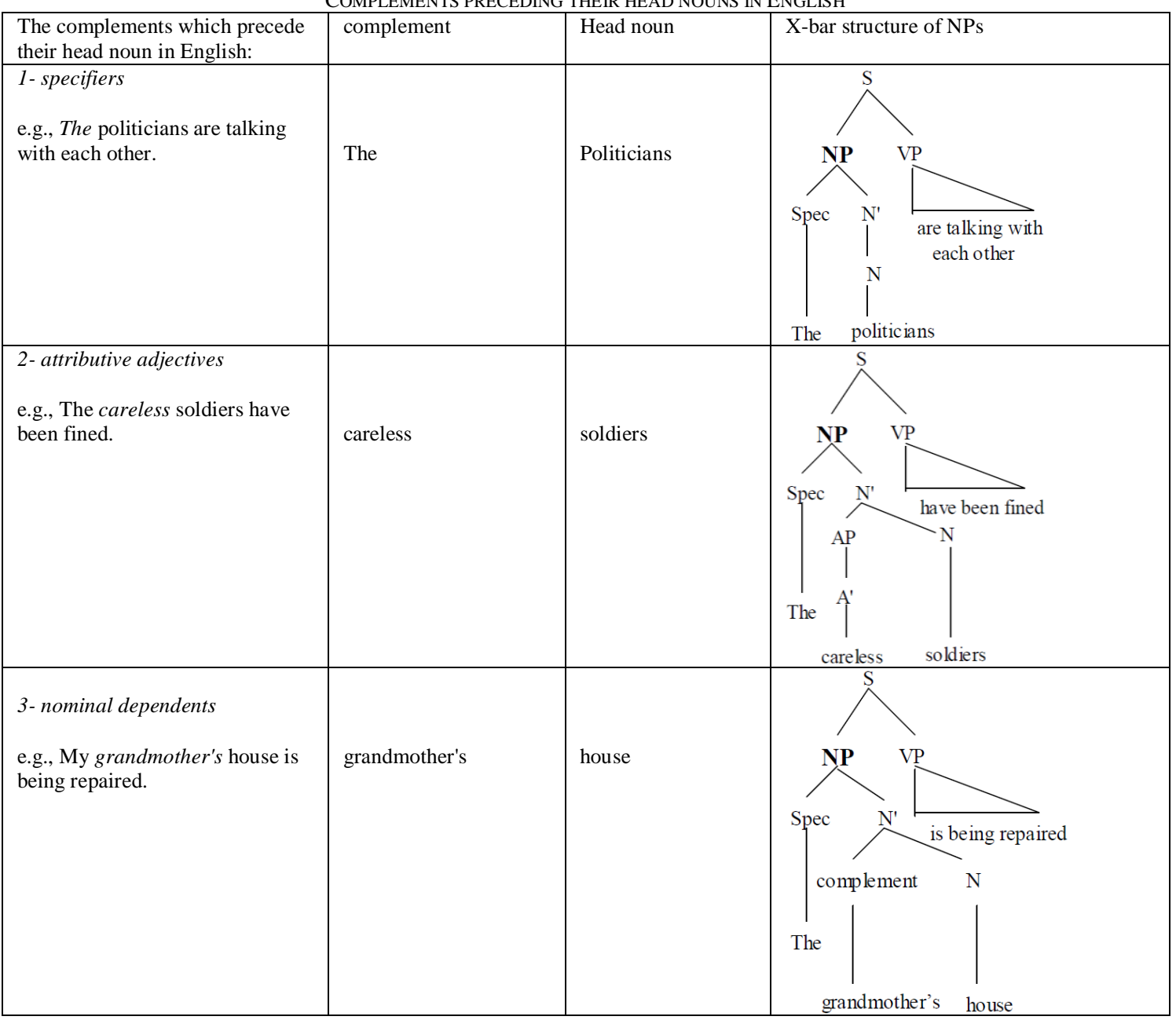

\section{Complements following their head nouns}

There are five complements which follow their head nouns in English NPs, which are: 1- Appositive phrases, 2Participial phrases, 3- Gerund phrases, 4- Prepositional phrases and 5- Adjective clauses. They are positioned after their head nouns as complements, based on the phrase structure rules of:

1- $X^{\prime \prime} \rightarrow$ Spec $X^{\prime} \& 2-X^{\prime} \rightarrow X$ complement

TABLE 3:

COMPLEMENTS FOLLOWING THEIR HEAD NOUNS IN ENGLISH (BASED ON MARCELLA, 1972: CHAPTERS 3, 5, 6 \& 10)

\begin{tabular}{|l|l|l|}
\hline The complements which follow their head noun in English: & Head noun & complement \\
\hline $\begin{array}{l}\text { 1- appositive phrases } \\
\text { e.g., Mr. Harris, in a hurry to get home, took a taxi from the airport. }\end{array}$ & Mr. Harris & in a hurry to get home \\
\hline $\begin{array}{l}\text { 2- participial phrases } \\
\text { e.g., The girl talking to the teacher is very intelligent. }\end{array}$ & The girl & talking to the teacher \\
\hline $\begin{array}{l}\text { 3- gerund phrases } \\
\text { e.g., Her cleaning the house every day is not necessary. }\end{array}$ & cleaning & the house everyday \\
\hline $\begin{array}{l}\text { 4- adjective clauses } \\
\text { e.g., Here is a book which describes animals. }\end{array}$ & book & which describes animals \\
\hline $\begin{array}{l}\text { 5- Prepositional phrases } \\
\text { e.g., reason of the war }\end{array}$ & reason & of the war \\
\hline
\end{tabular}

So, in English, more NPs, are ordered based on the phrase structure rule of $X^{\prime} \rightarrow X$ complement and hence, their NPs are considered head-initial.

\section{Phrase structure of VPs}

In the VP of English, the head verb appears on the left of the complement. 


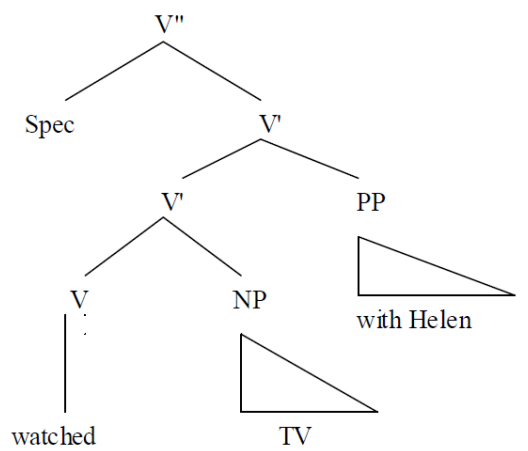

A) English PP: In the winter

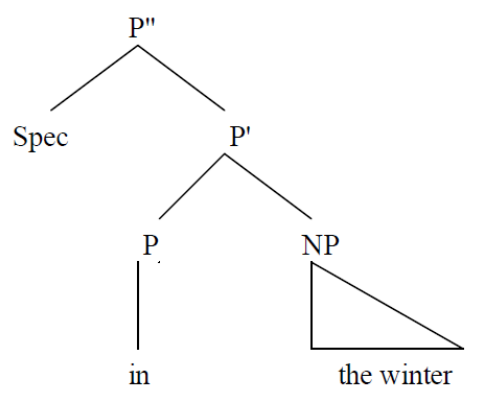

\section{Phrase structure of APs}

In APs, the head adjective is the most important element in the phrase and the rest are its complement(s); in indeed good, it is considered head-final, but in jealous of Jack, head-initial. It is dealt more in the following sections:

\section{Why is English AP head-initial?}

In most of the English APs, the head adjective as shown below, precedes its complements and that is why in English, adjectives are considered head-initial.

A) Some of the complements which follow the head adjective in English are:

1- prepositional phrases: envious of someone

2- enough (adv): warm enough

3- that clause: so beautiful that

B) Some of the complements which precede the head adjective in English are:

Determiners: rather cold

English AP: Quite fond of the girl

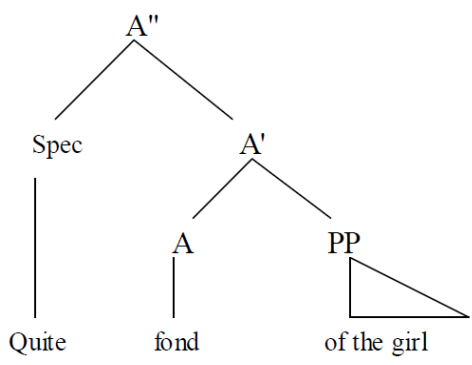

\section{CONCLUSION}

There are five complements in English NPs such appositive phrases, participial phrases, gerund phrases, propositional phrases and adjective clauses which follow their head nouns and three complements such as specifiers, attributive adjectives and nominal dependents which precede them. Since the numbers of following complements are more than the preceding ones, then English is considered head-initial in NP. So, in English, more NPs, are ordered based on the phrase structure rule of $X^{\prime} \rightarrow X$ complement and hence, its NPs are considered head-initial as following details.

In the VP of English, the head verb appears on the left of the complement and there is no other choice for this phrase normally. 


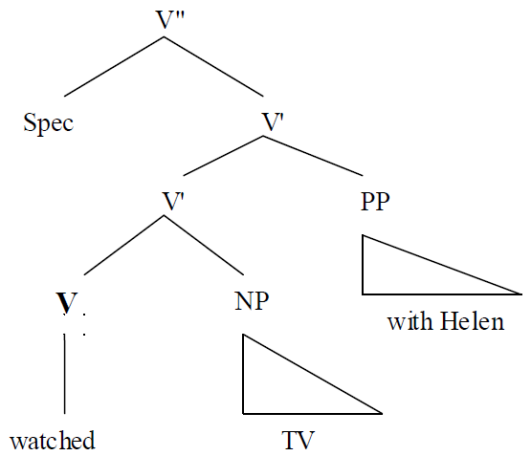

The head preposition appears on the left of the complement in English and there is no other choice for this phrase normally.

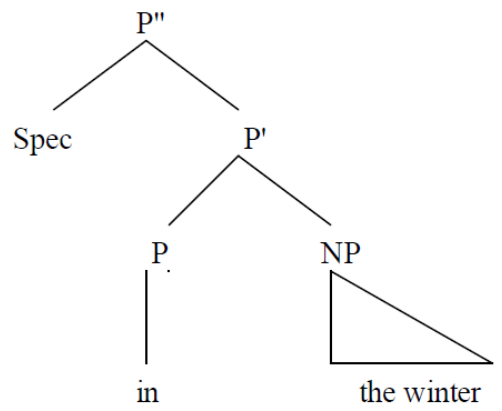

In most of the English APs, the head adjectives precede their complements, in other words the number of following complements is more than the preceding ones and that's why English adjective phrases are considered as head-initial. While prepositional phrases (e.g., envious of someone), enough as an adverb (e.g., warm enough) and that clauses (e.g., so beautiful that) follow their head adjectives in English, the determiners (e.g., rather cold) are the complements which precede their head adjectives in English as in the following diagram:

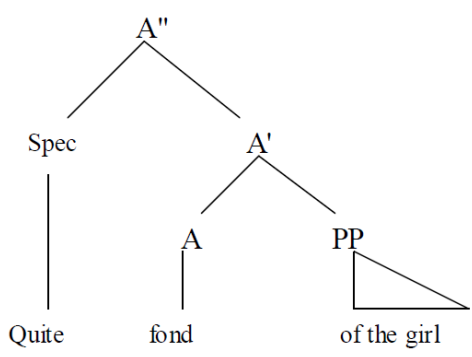

As it is shown in the above diagram, the determiner quite precedes the head adjective fond and the PP of the girl follows the head adjective fond.

To sum up, we see that what Radford (2006) expresses regarding English head parameters which normally precede their complements has enough evidence for English to be regarded as a head initial language.

\section{REFERENCES}

[1] Chomsky, Noam. (1970). Remarks on Nominalization. In R. Jacobs \& P. Rosenbaum (Eds.), Readings in English Transformational Grammar, pp. 184-221.

[2] Chomsky, N. (1972). Studies on semantics in generative grammar. The Hague: Mounton.

[3] Chomsky, N. (1976). On the nature of language. In S. R. Harnad and H. D. Steklis and J. Lancaster (Eds.), Origins and Evolution of Language and Speech. Annals of the New York Academy of Sciences, Volume 280, pp. 46-57.

[4] Chomsky, N. (1986). Knowledge of language (its nature, origin and use). Praeger: New York Press.

[5] Chomsky, N. (1988). Lectures on Government and Binding. Foris, Dordrecht.

[6] Chomsky, N. (2001). Beyond Explanatory Adequacy (MIT Occasional Papers in Linguistics). Cambridge, Mass: MITWPL Press.

[7] Chomsky, N. (2005). Three Factors in Language Design. Linguistic Inquiry. 36, 1-22.

[8] Cook, V.J. (1988). Chomsky's Universal Grammar. Oxford: Black well Publishers.

[9] Cook, V.J. \& Newson, M. (1996). Chomsky's Universal Grammar (An introduction). Oxford: Blackwell Press.

[10] Cook, V.J. \& Newson, M. (2007). Chomsky's Universal Grammar: An introduction. Oxford: Blackwell Press.

[11] Crystal, D. (2003). A Dictionary of Linguistics \& Phonetics. Oxford: Blackwell Press. 
[12] Farrokhpey, M. (1999). Government and Binding (Chomsky's Language Theory). Tehran: Sokhan Press.

[13] Haegeman, L. (2008). The syntax of adverbial clauses and the licensing of Main Clause Phenomena. Truncation or intervention? Paper presented at the $31^{\text {st }}$ GLOW Conference, Newcastle.

[14] Marcella, F. (1972). Modern English. Prentice-Hall, New Jersey.

[15] Radford, A. (2006). Minimalist Syntax: Exploring the structure of English. Cambridge: Cambridge University Press.

[16] Tallerman, M. (1998). Understanding Syntax. New York: Oxford University Press.

Zeinolabedin Rahmani received his BA in English Language Teaching from Mazandaran University and his MA in Applied Linguistics from Birjand University; He has also published many articles on different aspects of linguistics. His interested areas of research are: Syntax, Language Teaching, Language Learning and Discourse Analysis. He is a Part-Time teacher of Payamnour and Sama Universities in Iran, Qaemshahr and he is also the director of Zabanpazhouhan English teaching Institute.

Seyed Jalal Abdolmanafi (Rokni) is assistant professor at Golestan University, Iran. He has been teaching English at different universities for over ten years. He has published some articles and attended conferences at international levels. His areas of interest lie in second language acquisition, form-focused instruction and language teaching methodology. 